\title{
MUdANÇA ORGANIZACIONAL: UM ESTUDO DE CASO NA INDÚSTRIA FARMACÊUTICA
}

\author{
Roberta Krenski Silva \\ roberta.krenski@outlook.com \\ Centro Universitário Metodista - IPA
}

\section{RESUMO}

A análise do comportamento dos colaboradores em períodos de mudança organizacional é algo essencial para gestores dentro do meio corporativo. A gestão da mudança com foco em tecnologia da informação é um tema amplo e atual. Mudar processos administrativos e a maneira como eles são executados através de Sistemas de Informação requer não somente habilidade técnica dos envolvidos, mas também, apoio e planejamento por parte das organizações. Desta forma, buscou-se compreender qual era a percepção dos colaboradores de uma indústria farmacêutica de Porto Alegre frente ao processo de mudança, decorrente da migração do sistema de gestão ERP do fornecedor TOTVS Datasul para o da SAP. Objetivando entender este problema, tanto pelo olhar destes colaboradores quanto pelo de um gestor de área, foram necessárias a compreensão de quais foram as reações encontradas neste período e dos pontos que seriam determinantes para o sucesso durante a mudança organizacional. Para atingir estes objetivos, utilizaram-se dois instrumentos de pesquisa: um aplicado aos colaboradores e o outro, ao gestor. Ao final desta pesquisa, constatou-se que as organizações necessitam atentar para as pessoas em períodos de mudança, pois, para atingir o resultado almejado, é necessário que os colaboradores desempenhem as atividades estipuladas. Além da percepção de que são imprescindíveis as máquinas para cumprir os processos, por detrás delas, há pessoas que têm angústias e medos e que se veem ameaçadas pela velocidade com que as informações mudam.

PALAVRAS-CHAVE: Mudança organizacional. Gestão da mudança. Comportamento. Tecnologia da informação. Sistemas de gestão. 


\section{ORGANIZATIONAL CHANGE: A CASE STUDY IN THE PHARMACEUTICAL INDUSTRY}

\section{ABSTRACT}

Employees' behavior analysis, when the organization is going through periods of changes, is very important to the managers in the corporate environment. Changing management, focusing on information technology, is a broad and current theme. Changing administrative processes as well as the way they are run through Information System require not only technical abilities of people involved, but also organizations' support and planning. Thus, we tried to understand employees' perception of a pharmaceutic industry in Porto Alegre, considering the changing process, generated by the migration to the ERP management system. Aiming to understand the problem, through employees as well as area manager's perception, it was necessary to comprehend their reactions in this period and the most important facts to be successful during this organizational transformation. In order to achieve the objectives, two instruments were used: one, to the employees and the other to the manager. At the end of the research, we verified that organizations need to center their attention to people in the periods of change, since, aiming to achieve the expected results, it is necessary that employees perform the established activities. Apart from the perception that machines are essential to accomplish the process, behind them, there are people who have anxieties and fears and see themselves under threat by the velocity that information changes.

KEWORDS: Organizational change. Changing management. Behavior. Information technology. System management.

\section{INTRODUÇÃO}

Segundo Laudon e Laudon (2014) é imprescindível, para que as empresas obtenham sucesso, o uso assertivo da informação disponível. Porém, antes de ter relevância, a informação é tratada apenas como um dado, e este, conforme Caiçara Junior (2011), é definido como o acontecido de forma bruta e que ainda não possui importância para aqueles que o tem em mãos.

Frente a necessidade de tratar as informações a favor dos seus interesses, as empresas partem em busca da Tecnologia da Informação (TI). Laudon e Laudon (2014) a definem como 
sendo toda a estrutura física e todo o programa computacional que uma organização faz uso para alcançar seus objetivos. Conforme Souza e Zwicker (2009), o conjunto de meios pelos quais uma organização adquire, retém e processa os dados e, assim, os transforma na informação desejada é conhecido como Sistema de Informação (SI).

Dentro desse contexto de SI, está o Enterprise Resource Planning (ERP), que, por sua vez, para Souza e Zwicker (2000), é um sistema de informação integra diferentes informações setoriais de uma empresa. Os ERPs são softwares que, para Laudon e Laudon (2014), podem ser compreendidos como um conjunto de instruções que foram trabalhadas no detalhe e programadas anteriormente.

$\mathrm{O}$ ato de implantar um sistema de informação ERP não é algo simples, seja em pequenas ou em grandes empresas. Toda vez que se toma a decisão de abrir um novo negócio, é primordial pensar na escolha do software a ser utilizado e quando se decide fazer a migração de um ERP já presente dentro da empresa, o processo pode tornar-se algo crítico também. Em ambas as situações, os pontos fundamentais são: saber repassar as informações de uso aos colaboradores da empresa; gerir a resistência ao aprendizado e a mudança, e criar novos processos.

Frente às considerações apresentadas, este estudo objetivou abordar o processo de mudança organizacional durante a implantação de um Sistema de Informação Gerencial (SIG). Esta empresa migrou do ERP Enterprise Management System (EMS) da Datasul para o R/3 da System Analyisis and Program Development (SAP).

\section{FUNDAMENTAÇÃO TEÓRICA}

Para que se tenha clareza quanto ao conceito de um Sistema de Informação (SI), é necessário compreender a distinção 
entre dado e informação, bem como a caracterização de conhecimento e sistema. Neste sentido João (2014) diferencia os primeiros revelando que dados são fatos ocorridos em sequência que não passaram, até o momento, por algum tipo de análise e tratamento. E enquanto que, para o autor, a informação é um dado que já passou pelo processo de organização.

Já Souza e Zwicker (2009) reforçam o papel da informação dentro das organizações ao retratarem que, mesmo que ela não esteja ligada de forma direta ao produto desenvolvido pelas empresas, deve ser compreendida como um insumo para o processo de desenvolvimento do mesmo. Pois, conforme os autores, a informação conecta e coordena as diferentes tarefas indispensáveis para o processo produtivo, pois gera conhecimento.

Os sistemas de informação nas empresas passaram, de acordo com Caiçara Junior (2011), a ser condição para sobrevivência das mesmas a partir de 1990. O que anteriormente, segundo o autor, era uma grande vantagem competitiva frente a concorrência, hoje é visto como mais uma prática do dia a dia nas organizações aplicável para aqueles que necessitam de parâmetros para tomar decisões assertivas. Para Davenport (2002, p. 18) “da contabilidade à produção, das vendas aos serviços os módulos de um sistema integrado dá suporte a milhares de atividades de negócios."

A implantação de um sistema de gestão pode ser compreendida como o processo pelo qual os módulos de um sistema são colocados em atividade e, para que isso ocorra, é necessário que haja parametrizações (definição de métricas a serem utilizadas) e customizações (adaptações dos produtos conforme o gosto do cliente), com a finalidade de adequar o sistema à realidade da empresa (MENDES FILHO; TEIXEIRA, 2005).

A congruência entre a organização e as características oferecidas pelo ERP devem estar presentes na implantação 
do sistema, de acordo com Souza e Zwicker (2000). Para os autores, o pacote adquirido pela empresa é julgado como uma solução para atender aos requisitos propostos por ela e, também, pelo o que é considerado como necessidade e expectativa das pessoas que farão uso do ERP dentro deste ambiente organizacional.

Quase todos os sistemas ERP que há no mercado têm as mesmas funcionalidades básicas para atenderem o que uma empresa demanda, conforme Haberkorn (2008). O grande diferencial, para o autor, está em saber implantar corretamente e capacitar os usuários.

Ao trazer as razões que fazem uma empresa aceitar passar pelo complexo processo de implantação de um sistema ERP, Santos (2013) descreve que a busca pela padronização de dados e de processos, bem como a mudança continuada, podem ajudar a organização a se posicionar frente à concorrência.

Neste contexto de abordagem sobre o ERP, é fundamental que, ao menos para essa pesquisa, sejam apresentadas algumas características da fornecedora alemã SAP. De acordo com Valentim et al. (2014) a SAP se mantém, desde a sua criação, entre as líderes no fornecimento de software atendendo cerca de 48 mil empresas no mundo. Ao adentrar nos termos relacionados ao cotidiano de uma organização, Luz (2003) traz que, para enxergar a cultura organizacional de uma empresa, basta virar a atenção para o comportamento de todos os grupos e indivíduos ali presentes. Para tornar a cultura de uma organização visível para todos os colaboradores, Muchinsky (2004) apresenta que os processos de comunicação são fundamentais, porque é por meio da comunicação que a cultura é apresentada.

Schein (2009) argumenta que um dos principais erros cometidos pelas organizações é o de querer tornar algo simples o entendimento de sua cultura dando ao entender que se trata somente de um direcionador do comportamento das pessoas. 
O autor cita que a percepção da cultura envolve justamente as questões que são visíveis e invisíveis aos demais.

Relacionando o clima à cultura de uma organização, Stefano, Zampier e Maçaneiro (2007) tratam que o clima organizacional é notado dentro das empresas como uma característica do próprio ambiente. Os autores salientam que o mesmo é resultado da cultura organizacional encontrada no local e que os aspectos encontrados nela tendem a influenciar o comportamento dos colaboradores.

Chiavenato (2005b, p. 75) revela que "o clima organizacional influencia o estado motivacional das pessoas e por ele é motivacionado." Para Chiavenato (2005a) o clima organizacional, além do poder exercido sobre a motivação, atua também sobre o desempenho dos colaboradores e a sua satisfação com o trabalho que executam.

No que diz respeito à mudança, Banov (2013) traz que esta é um grande desafio universal e que a mesma é algo necessário para a sobrevivência e o crescimento a todos.

O posicionamento das pessoas e das empresas, de acordo com Banov (2013), frente aos períodos de mudança é compreendido por meio da resiliência ou na parada perante à possibilidade de variações. Para Banov (2013, p. 8) "a resiliência refere-se à capacidade de absorver as mudanças e aproveitar as oportunidades. Trabalhar a resiliência significa aumentar a rapidez para processar as mudanças."

A propor uma mudança organizacional, as empresas precisam estar cientes de que irão passar por um processo contínuo de mudança, em razão de não ser uma iniciativa sozinha, e sim um processo que age sob a organização. Pois reestrutura processos, modifica a cultura, a maneira como são feitas as atividades diárias e como os funcionários atuam em seu trabalho (CAPELLI, 2009). Entretanto, sempre haverá um preço a ser pago quando se propõe mudanças em um ambiente 
organizacional. De um âmbito geral, é possível dizer que os humanos sentem dor nesses momentos em que são forçados a mudar e se moldar conforme as condições do local aonde estão inseridos (KOTTER, 1997).

Ao abordar este tópico dentro do contexto desta pesquisa, Rodriguez e Ferrante (2000, p. 99) retratam que implementação de tecnologias está condicionada às capacidades que os recursos humanos têm de "inter-relacionamento pessoal, habilidade para a mudança e criatividade." Os autores finalizam dizendo que esses fatores estão ligados ao fato de existir resistência à mudança e que eles devem ser levados em consideração antes da mudança ser proposta.

Os gestores têm de se prepararem para lidar com a resistência em momentos de mudança, pois, conforme Hehn (1999), as pessoas resistem a ela. Seja a mudança benéfica ou não, as pessoas resistem. Para Hehn (1999, p. 102) mudar "implica em sair da zona de conforto onde a memória é o instrumento mais usado para agir e ter sucesso e entrar em uma região onde é preciso aprender, criar e pensar." O autor salienta que é natural que os indivíduos sintam-se desconfortáveis nesse processo, e que alguns demonstrem mais resistências do que os outros, pois o patrimônio intelectual construído para direcionar suas ações nas rotinas diárias de trabalho terá de ser refeito e isto implica, além de tudo, em perda do poder sobre os demais colegas de trabalho.

Segundo Hehn (1999), que é um autor especializado em abordar mudanças organizacionais relacionadas às implantações de ERP, as empresas possuem duas possibilidades: atuar alterando os elementos estruturais ou alterando as pessoas. Ainda de acordo com o autor, há um modelo de gestão da mudança baseado na ruptura dos modelos mentais estabelecidos pelas pessoas. Dentro desse modelo proposto, há a percepção trazida por Senge (2006), o qual define que estes modelos men- 
tais são imagens, pressupostos e histórias que os indivíduos vão somando ao longo de suas vidas. O autor destaca que os modelos mentais influenciarão decisões tomadas pelo resto da vida; que os indivíduos não têm a percepção do quanto isso os influencia e que são tidos como verdades inquestionáveis.

Ao gerir a mudança é fundamental que se tenha atenção à quebra dos modelos mentais. A tarefa de fazer pessoas adultas desaprenderem os ensinamentos que carregam ao longo de sua vida profissional é uma tarefa árdua (HEHN, 1999).

Com o passar do tempo, segundo Hehn (1999), os indivíduos percebem de que seus modelos mentais não são mais a realidade vivida pela organização, mas, sim, a sua própria interpretação do mundo onde habitam. Com isso os indivíduos desapegam de suas crenças e tendem a considerar as novas alternativas a serem colocadas em prática. Para Hehn (1999) estas poderão não ser as crenças dos colaboradores, mas serão a interpretação da nova realidade que é mais adequada do que a anterior.

\section{METODOLOGIA DE PESQUISA}

O método utilizado para esta pesquisa foi um estudo de caso, visando a expor o problema em questão através de enfoque quantitativo, ao descrevê-lo, e qualitativo, ao explorá-lo. No que tange às abordagens, a quantitativa teve o intuito de descrever um fato dentro da Empresa XYZ, e, para Marconi e Lakatos (2006), neste tipo de pesquisa, são utilizados instrumentos, a fim de coletar dados a partir de uma amostra, para posterior análise por meio de instrumentos estatísticos. Já a abordagem qualitativa objetivou explorar o comportamento e as reações dos indivíduos dentro da empresa em questão. Essa abordagem é definida por Malhotra (2006, p. 155) como uma "metodologia de pesquisa não-estruturada e exploratória, baseada em pequenas amostras que proporciona percepções e compreensão do contexto do problema." 
Para que fosse realizada a abordagem quantitativa, foram questionados dezesseis participantes das atividades do projeto de migração do sistema de gestão ERP e oriundos das seguintes áreas: contabilidade, contas a pagar e a receber, custos, distribuição, fiscal, qualidade e tecnologia. A abordagem qualitativa também contou com as respostas do gestor da área de Planejamento e Controle da Produção (PCP), escolhido, em razão de possuir a maior equipe dentro da Empresa XYZ. Todas essas amostras, dentro de uma população de, aproximadamente, cento e cinquenta colaboradores, atuantes na Empresa XYZ, localizada no Município de Porto Alegre, no Estado do Rio Grande do Sul, responderam aos instrumentos entre os meses de agosto a setembro de 2016.

Na presente pesquisa foi aplicado, aos colaboradores, um questionário (Apêndice A) de escala tipo Likert. Cada ponto desta escala equivale a um valor numérico que, no final das afirmações, foi quantificado. Esse instrumento contou com 21 questões. Por fim, foi entregue a um gestor de área outro questionário (Apêndice B), com o propósito de, também, explorar a percepção destes quanto ao fenômeno em foco. Foram aplicadas cinco perguntas ao responsável pelo setor.

Após a coleta, os dados foram tabulados afim de tornar possível a visualização dos itens de maior pontuação (Concordo Plenamente) e menor pontuação (Discordo Plenamente). Para esse cálculo, foi utilizado o número de respondentes da alternativa, multiplicado pelo "valor" da escolha (1 - Discordo Plenamente; 2 - Discordo Parcialmente; 3 - Indiferente; 4 - Concordo Parcialmente e 5 - Concordo Plenamente). Após o cálculo, os itens foram classificados entre os dois que tiveram maior e menor total acumulado. 


\section{RESULTADOS}

Buscando identificar as principais reações dos colaboradores durante o processo de mudança organizacional foram aplicadas sete afirmações. Para tal finalidade, se expõe na Tabela 1, as duas sentenças que tiveram maior acumulado, isto é, aquelas que os colaboradores tiveram maior nível de aceitação.

Tabela 1 - Maiores acumulados das principais reações dos colaboradores

\begin{tabular}{lcc}
\hline \multicolumn{1}{c}{ AFIRMAÇÃO } & ACUMULADO & POSIÇÃO \\
\hline $\begin{array}{l}\text { 1. Mesmo sob pressão, cooperei } \\
\text { para que as atividades ligadas ao } \\
\text { projeto de migração ocorressem. }\end{array}$ & 77 & 1 \\
$\begin{array}{l}\text { 6. Me adaptei às mudanças que } \\
\text { ocorreram na empresa em razão } \\
\text { da troca do sistema. }\end{array}$ & 73 & 2 \\
\hline
\end{tabular}

Fonte: Elaborada pela autora.

Após a conclusão do projeto de migração do sistema, a maioria dos colaboradores questionados tem a percepção, de acordo com a Tabela 1, que cooperaram, para que as atividades, ligadas ao projeto de migração, ocorressem. Conforme a segunda afirmação que obteve maior pontuação, verifica-se que eles estão adaptados às mudanças que aconteceram na empresa, em razão da troca do sistema. Esse ponto de vista vai ao encontro do que foi sugerido por Banov (2013), ao dizer que se ambientar à mudança é algo necessário para a sobrevivência e o crescimento de todos no ambiente organizacional.

A Tabela 2 também trata das principais reações dos colaboradores durante o período de migração do ERP, porém constam os dois elementos que tiveram a menor pontuação entre as seis afirmações apresentadas. 
Tabela 2 - Menores acumulados das principais reações dos colaboradores

\begin{tabular}{lcc}
\hline \multicolumn{1}{c}{ AFIRMAÇÃO } & ACUMULADO & POSIÇÃO \\
\hline $\begin{array}{l}\text { 7. Priorizava as atividades ligadas } \\
\text { ao projeto de migração do sistema }\end{array}$ & 39 & 1 \\
$\begin{array}{l}\text { somente se meu gestor solicitava. } \\
\text { 3. Senti entusiasmo para lidar com }\end{array}$ & & \\
$\begin{array}{l}\text { a mudança organizacional durante } \\
\text { a migração do sistema. }\end{array}$ & 57 & 2 \\
\hline
\end{tabular}

Fonte: Elaborada pela autora.

Com base nos somatórios da Tabela 2, nota-se que o primeiro item colocado se relaciona à priorização das atividades do projeto de migração somente quando o gestor a solicitava. A compreensão disto, conforme Banov (2013), ocorre pelo fato de envolvidos no projeto de migração terem apresentado resiliência.

Na segunda posição das afirmações da Tabela 2, há o entendimento de que os questionados não sentiram entusiasmo para lidar com a mudança organizacional durante a migração do ERP. A percepção desse item é destacada por Hehn (1999, p. 102), ao revelar que mudar "implica sair da zona de conforto, onde a memória é o instrumento mais usado para agir e ter sucesso e entrar em uma região onde é preciso aprender, criar e pensar". Hernandez e Caldas (2001) contribuem também para esse entendimento, ao exporem que as pessoas vão atrás de mensagens que contenham um conteúdo agradável e recusam aquilo que lhes parecem ameaçadoras.

Visando identificar, sob a ótica dos colaboradores, quais são os fatores críticos para o sucesso em um processo de mudança organizacional, foram aplicadas oito afirmações, conforme a Tabela 3, com as duas afirmações de maior soma entre as que foram disponibilizadas. 
Tabela 3 - Maiores acumulados dos fatores críticos para o sucesso

\section{AFIRMAÇ̃̃O}

8. Ter um líder para conduzir os processos de mudança organizacional é fundamental para o sucesso das atividades.

15. A organização deve fornecer para todos os colaboradores (mesmo não estando inseridos nas atividades ligadas ao projeto) as informações

referentes às mudanças que ocorrerão.

Fonte: Elaborada pela autora.

Para a amostra, o papel do líder é o principal ponto determinante para se obter sucesso nas atividades (Tabela 3). O entendimento de que uma liderança é fundamental na condução da mudança organizacional é explicado por Hehn (1999), já que as lideranças devem assumir o seu papel e trabalhar lado a lado da consultoria e demais envolvidos, a fim de assegurar o sucesso das tarefas. $\mathrm{O}$ autor traz ainda que um líder não deve se limitar a escolher os seus representantes que atuarão junto à empresa de consultoria. A segunda afirmação, expressa na Tabela 3, trata da importância da comunicação das atividades relacionadas à mudança organizacional não só para os envolvidos nos processos pertinentes, mas também, a todos da organização. Para que isto ocorra, conforme Hehn (1999) é imprescindível que se ofereça possibilidade para que todos discutam as vantagens e as desvantagens da mudança sob os seus pontos de vista.

Ainda ao tratar dos fatores críticos para o sucesso em períodos de mudança, constam, na Tabela 4, os itens que obtiveram menor acumulado. 
Tabela 4 - Menores acumulados dos fatores críticos para o sucesso

AFIRMAÇÃO

ACUMULADO POSIÇÃO

14. O apoio psicológico para

implementar a mudança

é fundamental dentro da organização.

12. Durante o processo de mudança devem ocorrer encontros para falar sobre os benefícios que a colaboradores.

64 mesma trará para o dia a dia dos

Fonte: Elaborada pela autora.

Conforme os colaboradores questionados, o apoio psicológico não é algo fundamental em momentos de mudança organizacional nem a organização de reuniões para falar a respeito dos benefícios que a mudança trará para o dia a dia dos colaboradores. Entendimentos estes que discordam do que foi dito por Silva e Vergara (2003), os quais argumentaram que é papel, sim, das organizações possibilitar que os envolvidos com a mudança tenham um momento para expor suas angústias e medos, decorrentes dos períodos de mudança organizacional.

A abordagem direcionada ao gestor de área teve o objetivo de identificar quais foram as principais reações de sua equipe que antecederam e sucederam a migração do sistema ERP. Para sanar este questionamento, o gestor respondeu a cinco perguntas abertas. O mesmo destacou que "quando ocorreu o anúncio da migração de sistema para a equipe, foram identificados, principalmente, dois tipos de comportamentos: curiosidade e receio." Como enfatiza o gestor, "todos funcionários da equipe demonstraram interesse em conhecer o novo sistema (alguns um pouco mais do que os outros)". Todavia, entre os seus colaboradores com mais tempo de empresa, "foi possível identificar um certo receio, uma vez

Remas - Revista Metodista de Administração do Sul, v. 2, N. 1, 2017 
que eles estavam bastante habituados com o sistema Datasul." Com o objetivo de diminuir esse tipo de impacto entre os colaboradores, Matos e Almeida (2007) expõem que deve ocorrer uma análise da cultura atual da organização e posterior verificação dos riscos que uma ruptura trará ao ambiente organizacional.

Para o gestor, "não houve resistência explícita da equipe à mudança". Mesmo vendo o empenho de sua equipe em cumprir as atividades do projeto, "em determinadas situações, os usuários demonstraram insegurança e até mesmo insatisfação". Segundo Capelli (2009), essas reações devem ser esperadas, quando são iniciados períodos de mudança organizacional. Ainda segundo o autor, esses períodos de transformações reestruturam processos, modificam a cultura organizacional, a maneira como são realizadas as atividades diárias e como os funcionários atuam em seu trabalho.

Seis meses após a migração do sistema, o gestor explica que "os colaboradores da área já estão familiarizados com o novo ERP". Para ele, "alguns ainda apresentam algumas dificuldades de utilizar o sistema, porém também há aqueles que se superaram e já buscam aperfeiçoar suas atividades com as novas ferramentas disponibilizadas com o SAP."No que diz respeito a como os colaboradores com mais tempo de empresa estão reagindo às mudanças organizacionais, para o gestor, "não foi percebida resistência ao uso do sistema, pois foram conscientizados sobre as ferramentas que o sistema novo possui e também por se tratar de uma mudança que já havia sido decidida pela companhia".

O responsável pela área ressaltou, ao abordar uma tarefa importante para aqueles que precisam gerir a mudança organizacional, que é a "conscientização da necessidade da mudança". Esse ato que é visto por Hehn (1999, p. 133) como a quebra dos modelos mentais e que, "quando isso é feito com sucesso, a própria organização se encarrega de realizar as demais transformações necessárias". Conscientizar para a mudança ocorre 
na abordagem do autor, quando é transmitida a importância de apresentar diferentes propostas de modelos mentais, valores e crenças em que a nova realidade da empresa será baseada, gerando, assim, condições para que os colaboradores testem os novos modelos mentais $e$ tenham a possibilidade de ver os resultados positivos que poderão ser atingidos com a mudança.

Os colaboradores tiveram de responder a seis perguntas para constatar quais foram as primeiras impressões dos mesmos quanto ao uso do ERP R/3. Com este intuito, se apresenta a Tabela 5 .

Tabela 5 - Maiores acumulados dasprimeiras impressões com o uso do SAP R/3

\begin{tabular}{lcc}
\hline \multicolumn{1}{c}{ AFIRMAÇÃO } & ACUMULADO & POSIÇÃO \\
\hline $\begin{array}{l}\text { 16. O uso do SAP enriquece meu } \\
\text { currículo profissional. }\end{array}$ & 79 & 1 \\
$\begin{array}{l}\text { 17. O uso do SAP traz benefícios } \\
\text { para a empresa. }\end{array}$ & 69 & 2 \\
\hline
\end{tabular}

Fonte: Elaborada pela autora.

Com maior somatório entre as seis afirmativas que tinham a intenção de responder esta questão, consta a que os colaboradores têm a noção do enriquecimento que a utilização de um ERP da SAP traz para o seu currículo. Essa consciência, de acordo com Valentim et al. (2014), é explicada pelo fato de a SAP estar, desde a sua criação, entre as líderes no fornecimento de softwares no mundo, atuando em mais de $120 \mathrm{mil}$ países e com 12 milhões de usuários finais. Os respondentes também concordam que usar o R/3 trouxe benefícios para a empresa o que, para Davenport (2002, p. 271), é compreendido pela "capacidade ampla e extensiva" que o produto oferece às empresas que optam por utilizá-lo. 
Os itens contaram com tendência à discordância são visualizados na Tabela 6 .

Tabela 6 - Menores acumulados das primeiras impressões com o uso do SAP R/3

\begin{tabular}{|c|c|c|}
\hline AFIRMAÇÃO & ACUMULADO & POSIÇÃO \\
\hline $\begin{array}{l}\text { 21. As rotinas diárias de processos } \\
\text { foram definidas de uma melhor } \\
\text { maneira no SAP em relação ao que } \\
\text { era com o sistema anterior. }\end{array}$ & 51 & 1 \\
\hline $\begin{array}{l}\text { 19. O SAP trouxe melhorias para } \\
\text { as minhas atividades dentro da } \\
\text { empresa. }\end{array}$ & 59 & 2 \\
\hline
\end{tabular}

Fonte: Elaborada pela autora.

Frente às afirmações, propostas para responder a esta pergunta, percebe-se que os questionados não têm a impressão de que as rotinas diárias de processos estão melhores definidas no R/3 em relação ao que eram no EMS, conforme a Tabela 6. Davenport (2002) critica essa questão, ao trazer que o sistema da SAP é de grande complexidade para os que o utilizam, em decorrência de sua integração entre os módulos disponibilizados. Para o autor, este é um possível limitador para aqueles usuários que utilizam regularmente o ERP da SAP, o R/3.

O segundo colocado é referente à discordância de que as atividades dos colaboradores tiveram melhorias após a mudança do sistema. Souza e Zwicker (2000) abordam essa questão, e relatam que as implantações de ERP, além de gerarem mudança no dia a dia dos colaboradores, modificam também a forma como os setores se relacionam dentro da empresa.

\section{CONSIDERAÇÕES FINAIS}

Mesmo que a mudança faça parte da evolução do ser humano, ainda é um período em que é necessária uma re- 
flexão de onde se está e para onde se vai. Embora pareça algo subjetivo, esta análise é fundamental, a fim de que se internalize a mudança.

A gestão da mudança organizacional é um fato presente no cotidiano das empresas, porém ainda deixada de lado nos momentos conturbados de transformações. No meio acadêmico, a mudança é um tema explorado e que tem ampla literatura, mas, talvez, pelo momento de ampla globalização, no qual há maior conectividade entre o homem e a máquina, seja necessário que o foco desses estudos caminhe em direção a esta relação e aos fatores que estão ligados a ela, como: a ansiedade e o medo de perder o poder sobre a informação.

Através deste trabalho, buscou-se abordar a percepção dos colaboradores de uma indústria farmacêutica de Porto Alegre frente ao processo de mudança organizacional, decorrente da migração do sistema de gestão ERP. Para isso, aplicou-se instrumentos de coletas de informações tanto para os colaboradores que participaram das atividades que eram ligadas ao projeto de migração do sistema quanto a um gestor de área, para trazer uma compreensão técnica sobre os sentimentos de alguns funcionários neste período.

A análise dessas informações possibilitou constatar, primeiramente, que os colaboradores, mesmo esperando maior apoio da empresa, cooperaram com as atividades ligadas ao projeto de migração. Entretanto, gostariam que houvesse um papel de liderança para conduzir este período. Também se identificou que os colaboradores têm a noção do quanto utilizar o SAP R/3 agrega valor ao currículo profissional e percebem que aquele trouxe benefícios para a gestão da Empresa XYZ.

Sob o olhar gerencial, constatou-se que os colaboradores demonstraram, de imediato, dois sentimentos no tocante à mudança organizacional que seria implantada: curiosidade e receio. 
Acerca das limitações desta pesquisa, notou-se que, talvez, os colaboradores questionados, com medo de expor os seus reais sentimentos, limitaram-se a respostas já esperadas. Do mesmo modo, percebeu-se que não há, até o momento, literatura extensa sobre o tema "gestão da mudança com foco em comportamentos presentes em período de alterações da tecnologia da informação". Em função disto, em certos momentos, esta pesquisa limitou-se a poucos autores.

Portanto, em relação às sugestões para as futuras pesquisas a serem realizadas a respeito do tema, estas devem se ater a continuar a aplicar instrumentos em empresas que têm períodos de mudanças organizacionais que envolvam sistemas e processos, para que, futuramente, haja maior embasamento teórico sobre este assunto. Ressalta-se que, para atingir o sucesso dentro de uma organização, não basta limitar-se somente a gerenciar os processos administrativos e fabris, mas também é preciso lembrar-se de que ainda há pessoas que realizam inputs nas máquinas e que essas mesmas pessoas possuem angústias e medos, em virtude de as informações mudarem de forma rápida, sem acompanhamento especializado e planejamento das atividades a serem desempenhadas.

A quebra de modelos mentais e a conscientização da necessidade de mudança são dois aspectos trazidos nesta pesquisa e que são a base para se construir a mudança. Além do fato de as organizações terem a percepção de que o sucesso, em períodos de mudança, depende do esforço empenhado pelos seus colaboradores, torna-se imprescindível que este seja um período de internalização da nova realidade, no qual haja momentos em que sejam compartilhados temas, como o andamento das atividades, qual o ponto em que a organização deseja chegar, o porquê de se realizar a mudança e, indispensavelmente, seja dado espaço para que os colaboradores exponham os seus sentimentos a respeito desse momento vivido. 


\section{REFERÊNCIAS}

BANOV, Márcia Regina. Mudanças organizacionais: o perfil da empresa e do colaborador. São Paulo: Atlas, 2013. 104 p.

CAIÇARA JUNIOR, Cícero. Sistemas Integrados de Gestão ERP: uma abordagem gerencial. 4. ed. Curitiba: Ibpex, 2011

CAPELLI, Andressa Lacerda. Mudança organizacional e fatores críticos de sucesso: estudo de caso no sistema FIERGS. 2009. 140 f. Dissertação (Mestrado) - Universidade Federal do Rio Grande do Sul, Porto Alegre, 2009.

CHIAVENATO, Idalberto. Gerenciando com as pessoas: transformando o executivo em um excelente gestor de pessoas. Rio de Janeiro, RJ: Elsevier, 2005. 335 p.

CHIAVENATO, Idalberto. Recursos humanos: o capital humano das organizações. 8. ed. São Paulo: Atlas, 2005.

DAVENPORT, Thomas H. Missão Crítica: obtendo vantagem competitiva com os sistemas de gestão empresarial. Porto Alegre: Bookman, 2002.

JOÃO, Belmiro N. Sistemas Computacionais. São Paulo: Pearson Education Brasil, 2014. 138 p.

HABERKORN, Ernesto. Gestão empresarial com ERP. 4. ed. São Paulo: TI Educacional, 2008. 410 p.

HEHN, Herman Frederico. Peopleware: como trabalhar o fator humano nas implementações de sistemas integrados de informação (ERP). São Paulo: Gente, 199. 167 p.

HERNANDEZ, José Mauro da Costa; CALDAS, Miguel P. Resistência à mudança: uma revisão crítica. RAE-Revista de Administração de Empresas, v. 41, n. 02, p. 31-45, abr-jun 2001. Disponível em: <rae. fgv.br/rae/vol41-num2-2001/resistencia-mudanca-revisao-critica>. Acesso em: 15 mai. 2016.

KOTTER, John P. Liderando mudança: um plano de ação do mais notável especialista do mundo em liderança nos negócios. 17. ed. Rio de Janeiro: Campus, 1997.

LAUDON, Kenneth C; LAUDON, Jane P. Sistemas de informação gerenciais. 11. ed. São Paulo: Pearson Education, 2014. 
LUZ, Ricardo. Gestão do clima organizacional. Rio de Janeiro: Qualitymark, 2003. 143 p.

MALHOTRA, Naresh K. Pesquisa de marketing: uma orientação aplicada. 4. ed. Porto Alegre: Bookman, 2006.

MARCONI, Marina de Andrade; LAKATOS, Eva Maria. Técnicas de pesquisa: planejamento e execução de pesquisas, amostragens e técnicas de pesquisa, elaboração, análise e interpretação de dados. 6. ed. São Paulo: Atlas, 2006.

MATOS, José Gilvomar R.; MATOS, Rosa Maria B.; ALMEIDA, Josimar Ribeiro de. Análise do ambiente corporativo: do caos organizado ao planejamento estratégico das organizações. Rio de Janeiro: e-papers, 2007. $473 \mathrm{p}$.

MENDES FILHO, Luiz Augusto; TEIXEIRA, Cristiane. Impactos relacionados à implantação de ERP: um estudo de casos comparados. Revista Gestão Industrial, Ponta Grossa, v. 01, n. 04, p. 69-76, out. 2005. Disponível em: <www.abepro.org.br/bibliotecalenegep2004_enegep0903_0028.pdf>. Acesso em: 17 abr. 2016.

MUCHINSKY, Paul M. Psicologia organizacional. São Paulo: Pioneira, 2004. 508 p.

RODRIGUEZ, Martius Vicente Rodriguez y; FERRANTE, Augustian Juan. Tecnologia de informação e gestão empresarial. 2. ed. Rio de Janeiro: E-papers, 2000.

SANTOS, Aldemar de Araújo. ERP e sistemas de informações gerenciais. São Paulo: Atlas, 2013. 109 p.

SCHEIN, Edgar H. Cultura organizacional e liderança. São Paulo: Atlas, 2009. $413 \mathrm{p}$.

SENGE, Peter M. A quinta disciplina: arte e prática da organização de aprendizagem. 22. ed. São Paulo: Best Seller, 2006.

SILVA, José Roberto Gomes da; VERGARA, Sylvia Constant. Sentimentos, subjetividade e supostas resistência à mudança organizacional. RAE-Revista de Administração de Empresas, v. 43, n. 03, p. 10-21, jul-set. 2003. Disponível em:

$<$ http://rae.fgv.br/rae/vol43-num3-2003/sentimentos-subjetividade-supostas-resistencias-mudanca-organizacional $>$. Acesso em: $30 \mathrm{abr}$. 2016. 
SOUZA, Cesar Alexandre; ZWICKER, Ronaldo. A tecnologia da informação e as organizações: um modelo para a análise de seus usos e impactos. Revista FACEF Pequisa, Desenvolvimento e Gestão, Franca, v. 12, n. 01, p. 33-51, jan. 2009. Disponível em:<periodicos. unifacef.com.br/index.php/facefpesquisa/article/view/3/199>. Acesso em: 10 mai. 2016.

SOUZA, Cesar Alexandre; ZWICKER, Ronaldo. Implementação de sistemas ERP:um estudo de casos comparados. In: ENCONTRO ANUAL DA ANPAD, 24., 2000, Florianópolis. Anais... Rio de Janeiro: ANPAD, 2000.Disponível em: <usuarios.upf.br/ ricardo/adi-567.doc>. Acesso em: 13 out. 2015.

STEFANO, Silvio Roberto; ZAMPIER, Marcia Aparecida; MAÇANEIO, Marlete Beatriz. Satisfação no trabalho e indicadores de clima organizacional: um estudo de multicasos na região central do Paraná. In: SEMINÁRIOS EM ADMINISTRAÇÃO, 10, 2007, São Paulo. Anais... São Paulo: Ed. da USP, 2007. Disponível em:

$<$ http://sistema.semead.com.br/10semead/sistema/resultado/trabalhosPDF/109.pdf>. Acesso em: 7 set. 2016.

VALENTIM, Onivaldo Aparecido et al. Análise comparativa entre a implementação do sistema ERP R/3 da SAP considerando os fatores críticos de sucesso descritos na literatura: um estudo de caso em uma empresa do segmento de bebidas. Revista Gestão \& Produção, São Carlos, v. 21, n. 1, p. 111-124, jan. 2014. Disponível em:

$<\underline{\text { http://www.scielo.br/scielo.php?pid=S0104530X2014000100008\&scr }}$ ipt=sci abstract\&tlng=pt. $>$. Acesso em: 5 nov. 2015. 


\section{APÊNDICE A}

1. Mesmo sob pressão, cooperei para que as atividades ligadas ao projeto de migração ocorressem.

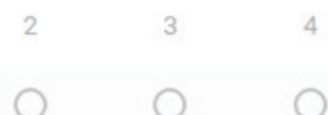

2. Tive estabilidade emocional para lidar com a mudança durante a migração do sistema.
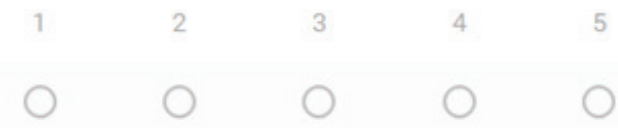

3. Senti entusiasmo para lidar com a mudança organizacional durante a migração do sistema.

Discordo

plenamente

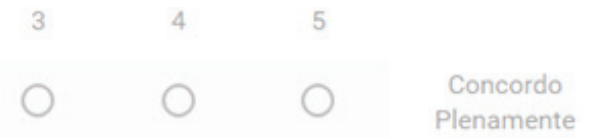

4. Cooperei com as atividades do projeto de migração do sistema, pois migrar o sistema foi melhor a ser feito para a empresa.

Discordo

plenamente

$\begin{array}{lllll}1 & 2 & 3 & 4 & 5\end{array}$

5. Cooperei com as atividades do projeto de migração do sistema almejando um futuro reconhecimento sobre as tarefas que eu desempenho.

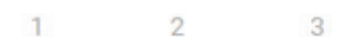




\section{DESAFIOS E OPORTUNIDADES DA LOGÍSTICA REVERSA DE ELETROELETRÔNICOS EM UMA OPERADORA DE CELULAR NA VISÃo DE GESTORES E USUÁRIOS}

6. Me adaptei às mudanças que ocorreram na empresa em razão da troca do sistema.

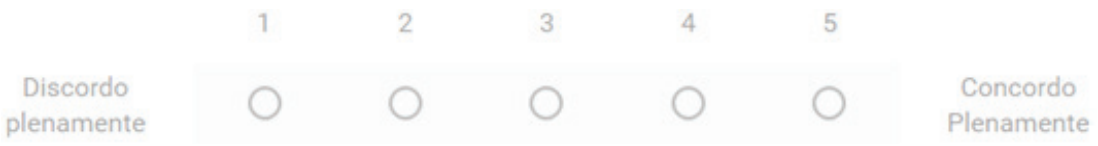

7. Priorizava as atividades ligadas ao projeto de migração do sistema somente se meu gestor solicitava.

\section{Discordo}

plenamente

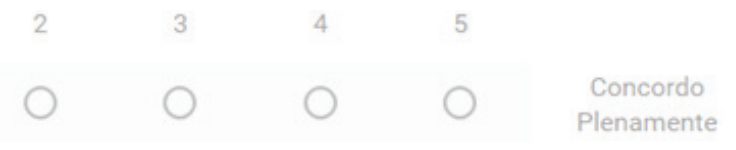

8. Ter um líder para conduzir os processos de mudança organizacional é fundamental para o sucesso das atividades.

Discordo

plenamente
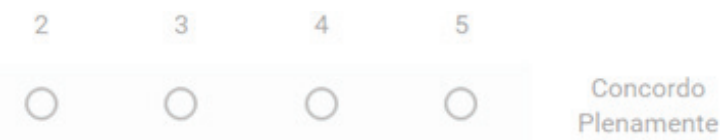

9. O período de adaptação às novas atividades organizacionais deve ser compatível com a complexidade das mesmas.

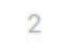

10. gressão da carreira, os colaboradores que se engajarem em
processos de mudança organizacional. 
11. É papel da organização oferecer programas de capacitação constantes aos colaboradores mesmo após o término da implantação da mudança organizacional.

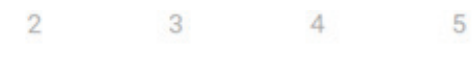

12. Durante o processo de mudança devem ocorrer encontros para falar sobre os benefícios que a mesma trará para o dia a dia dos colaboradores.

13. Os gestores têm de compreender quando seus subordinados estão engajados com a mudança que está sendo implantada e não conseguem atender todas as tarefas da sua antiga rotina.

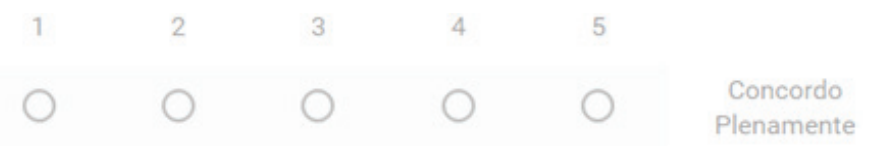

14. O apoio psicológico para implementar a mudança é fundamental dentro da organização.

15. A organização deve fornecer para todos os colaboradores (mesmo não estando inseridos nas atividades ligadas ao projeto) as informações referentes às mudanças que ocorrerão. 


\section{DESAFIOS E OPORTUNIDADES DA LOGÍSTICA REVERSA DE ELETROELETRÔNICOS EM UMA OPERADORA DE CELULAR NA VISÃo DE GESTORES E USUÁRIOS}

16. O uso do SAP enriquece meu currículo profissional.

Discordo

plenamente

$\begin{array}{llll}2 & 4 & 5\end{array}$

\section{5}

Concordo Plenamente

17. O uso do SAP traz benefícios para a empresa.

Discordo

plenamente

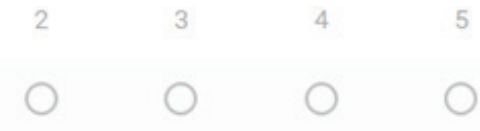

Concordo

Plenamente

18. Me sinto seguro ao desempenhar minhas tarefas diárias no SAP.

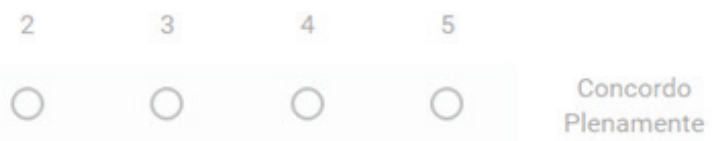

19. O SAP trouxe melhorias para as minhas atividades dentro da empresa.

Discordo

plenamente

$\begin{array}{llll}2 & 3 & 4 & 5\end{array}$

20. O fator integração de setores que existe com o uso do SAP traz benefícios para as minhas rotinas diárias de trabalho.

Discordo

plenamente

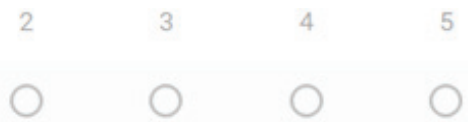

Concordo

Plenamente

21. As rotinas diárias de processos foram definidas de uma melhor maneira no SAP em relação ao que era com o sistema anterior. 


\section{APÊNDICE B}

1. No momento em que foi anunciada a migração do sistema, como sua equipe reagiu?

2. Durante o processo de mudança organizacional em decorrência da migração do sistema, quais foram as principais reações de seus colaboradores?

3. Houve resistência à mudança organizacional? Caso sim, como foi exposta por parte de sua equipe?

4. Agora, com a utilização do novo sistema, como seus colaboradores estão reagindo? Estão confortáveis com o novo sistema?

5. Com relação aos colaboradores que estão há mais tempo na empresa, é perceptível resistência quanto ao uso do novo sistema e das novas rotinas de trabalho? 